\title{
Study on Services of Chattogram Maa-O-Shishu Hospital
}

\section{Chinmoy Baidya ${ }^{1 *}$ \\ Nazmul Hasan ${ }^{2}$ \\ Kawsar Sultana}

'Department of Community Medicine Chattogram Maa-O-Shishu Hospital Medical College Chattogram, Bangladesh.

${ }^{2}$ Department of Anaesthesiology Chattogram Maa-O-Shishu Hospital Medical College Chattogram, Bangladesh.

\footnotetext{
*Correspondence to:

Dr. Chinmoy Baidya

Associate Professor

Department of Community Medicine Chattogram Maa-O-Shishu Hospital Medical College Agrabad, Chattogram, Bangladesh Mobile : +8801818173444

Email : chinmoy.baidya@yahoo.com
}

Date of Submission : 15.03 .2021

Date of Acceptance : 27.04 .2021

www.banglajol.info/index.php/CMOSHMCJ

\begin{abstract}
Background: Hospital services are the amenities provided by a hospital both for the patients and the workforces. Periodical assessment of hospital service quality discovers the demands and needs thus ensuring the development of the institution. The aim of the study to find out the problems regarding hospital services and its solution.
\end{abstract}

Materials and methods: This observational study was conducted among the health personnel of Chattogram Maa-O-Shishu Hospital from 01 July to 30 August 2019 and 01 January to 29 February 2020. Purposive sampling technique was followed to collect data from 100 randomly selected samples. They were interviewed with pretested questionnaire and data were managed manually.

Results: Different findings were drawn. These are: Lack of work dedication, responsibility, loyalty and internal co-operation among the staff (60\%). Lack of manpower including doctors, nursing staff, cleaners and few recruitments are not so experienced as to fulfill the demands of their duty (56\%). The number of beds is less compared to the number of patients who need them e.g. ICU, CCU, NICU, Paediatric ICU Adult medicine ward, etc. Hence patients are referred outside (46\%). Patient visiting hours and number of visitors not properly maintained. Visitors make noise, take food on patient's bed and sometime physically assault employees when they are asked to obey rules (40\%). However, overall job satisfaction of the respondents was $78 \%$.

Conclusion: Ascertaining the issues regarding the improvement of hospital services is mandatory. Quick detection and early solution would gain confidence by employees and beneficiary which would ultimately boost up the reputation of the hospital.

Key words: Hospital service; Health personnel; Patient.

\section{INTRODUCTION}

Hospital service is a term that refers to medical and surgical services and the supporting laboratories, equipment and personnel that make up the medical and surgical mission of a hospital or hospital system ${ }^{1}$. Chattogram Maa-O-Shishu Hospital (CMOSH) is a non-governmental organization run by public charity. Being a non-profit hospital, service quality should be of prime concern. Assessing the hospital service quality is similar to hospital service research. It has multidisciplinary aspects with the principal view to improve the health of the people ${ }^{2}$. Measuring hospital service quality at regular intervals is essential to review the current status and to identify problems. Detecting and prioritizing the pitfalls, service quality could be improved by proper planning and executing the action plan regarding hospital services. The purpose of the study to identify the problems regarding hospital service and find ways to improve the services. 


\section{MATERIALS AND METHODS}

It was an observational study conducted among the health personnel of Chattogram Maa-O-Shishu Hospital from 01 July to 30 August 2019 and 01 January to 29 February 2020. Sample size was 100 and collected by purposive sampling technique. Subjects were interviewedusing a pretested questionnaire and the data was managed manually.

\section{RESULTS}

Among the 100 respondents, majority (44\%) was $40-50$ years age group, followed by $28 \%$ were from below 30 years age group. Male respondents were $71 \%$ and female were $29 \%$. Majority ( $40 \%$ ) of the respondents were working for 1 year to 3 years, $34 \%$ were working from 6 months to 1 year in the institute. (Table I).

Table I : Socio-demographic characteristics of the study respondents

Characteristics Frequency $(\mathrm{n}=100) \quad$ Percentage $(\%)$

\section{Age}

$\begin{array}{lrr}<30 \text { years } & 28 & 28 \\ \text { 30-40 years } & 44 & 44 \\ \text { 40-50 years } & 17 & 17 \\ >50 \text { years } & 11 & 11 \\ \text { Sex } & & \\ \text { Male } & 71 & 71 \\ \text { Female } & 29 & 29 \\ \text { Duration of service } & & \\ <6 \text { month } & 10 & 10 \\ 6 \text { month-1 year } & 34 & 40 \\ \text { 1-3 years } & 40 & 12 \\ \text { 3-5 years } & 12 & 4 \\ >5 \text { years } & 4 & \end{array}$

In this study, $60 \%$ of the respondents complained about lack of work dedication, responsibility, loyalty and internal cooperation among their staff members.

To add to this, there was the shortage of man-power including doctors, nurses, cleaners etc. $56 \%$ complained that the few new workers that were recruited were not so efficient in their job and hence were unable to fulfill the work demands.

Patient visitors did not oblige by the rules on patient visiting hours and lack of staff made it difficult to control visitors properly.

On multiple occasions, visitors made noise, took food on to patient's beds and went as far as assaulting employees physically when asked to obey the rules. This was a complaint by $40 \%$ of the respondents. Due to this uncontrolled environment for hospital visitors, there have been complaints of thefts $(33 \%)$ in different wards of the hospital with some unfortunate cleaning staff being accused of stealing by visitors.
Other complaints included discrimination among workers by the superiors $(30 \%)$, inability to maintain work synchronization in the wards $(28 \%)$, feeling unsafe in the wards at night $(10 \%)$ and $5 \%$ of respondents complaining they were forced to do overtime.

During rush hour, there was a lack of adequate ticket counters (24\%). Number of beds in some departments such as ICU, CCU, NICU, PICU, adult medicine ward, etc. was less compared to the number of patients requiring admission resulting in patients being referred elsewhere (46\%). Likewise, there was a lack of office space for doctors, lack of adequate toilets, bedside teaching space, female prayer space and library space for reading, according to $15 \%$ of the respondents. Some doctors also complained about salary discrepancy according to government scale $(7 \%)$ and in some case patients were more likely to be referred outside despite the hospital having adequate manpower and facilities to treat such cases $(8 \%)$ (Table II).

Table II : Findings of the study respondents

Complaint*

Percentage (\%)

Lack of work dedication of the workers 60

Lack of manpower

56

Lack of decency among visitors

Staff discrimination $\quad 30$

Insecurity 10

Work synchronization not maintained 28

Forced to do overtime 5

Salary discrepancy $\quad 7$

Thefts in wards 33

Lack of adequate ticket counters $\quad 24$

Inpatient patient overflow $\quad 46$

Lack of space for different facilities $\quad 15$

Unexpected Referral 8

*Multiple responses exist.

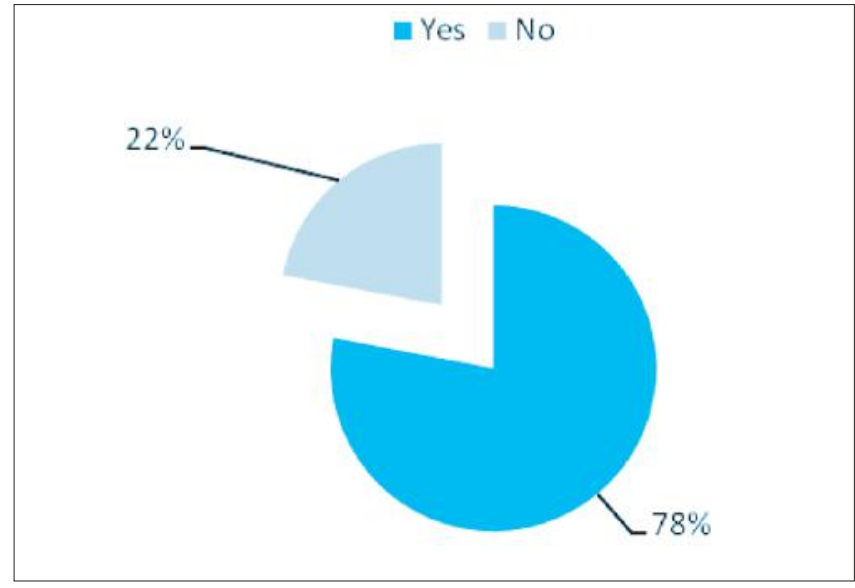

Figure 1 : Overall job satisfaction $(\mathrm{n}=100)$

Overall job satisfaction of the respondents was 78\% (Figure 1). 


\section{DISCUSSION}

In order to improve the quality of care at a healthcare facility, co-operation of both caregivers and receivers is essential. This paper was an attempt at identifying factors that would impede the quality of services given by healthcare professionals and provide suggestions to improve the situation in the least.

According to a study by Yang \& Fry, healthcare workers are at an increased risk of exhaustion due to increased work demands, limited salary, increased turnaround times and dire consequences for association with patient errors. As a result, they underwent many negative personal as well as organizational outcomes such as poor health, negative work attitudes, work conflicts, job dissatisfaction, absenteeism, psychological stress and medical errors due to this, all of which negatively affect the quality of healthcare ${ }^{3}$. Our study had findings that were relatable to this. Top three most common complaints by healthcare workers were lack of dedication, lack of man power and patient overflow. These in turn lead to raised aggression of patients and visitors providing a source for numerous litigations against healthcare workers. An older study conducted in Ontario, Canada, discusses about the restructuring of the healthcare system where a small number of highly skilled core staff were retained with less qualified staff on a contractual basis who could be hired and let go at will ${ }^{4}$. Among other advantages, this new method could keep medical professionals under continuous surveillance and evaluation. However, from a professional point of view it was doubtful if such a step would be effective since there would be an increase in the number of lay-offs and part time workers resulting in insecurity among the workers; coupled with heavy workload on the remaining staff.This attempt leads to various problems leading to a health crisis and increased use of the private sector where patients preferred to hire personal nurses and patient care assistants thus further increasing expenditure by the patients or their insurance companies.

Patient and visitor violence are quite common among hospitals across the world. From developing nations such as India to the developed nations such as the UK and Switzerland, multiple studies have been published regarding this issue $e^{5,6,7}$. In fact, 'healthcare workers are one of the most likely groups to experience aggression in the work place' ${ }^{6}$. These include verbal aggression, verbal threats and physical assault.One study conducted at an emergency department showed paramedics to be the most common group to be harassed followed by nurses and then doctors. About $67 \%$ of nurses, $63 \%$ of patient care assistants and $51 \%$ of physicians have been assaulted at least once $^{8}$. Nevertheless, assaults against workers in other hospital sectors cannot be overlooked. Hence, the management needs to provide violence prevention training to hospital workersspecific to their work settings as well as develop strict policies and procedures for staff to follow when dealing with such cases.
Lack of space for various uses was another complaint in this study. In developed nations with improved healthcare systems, hospital capacity planning is an important feature. When reforming a hospital, proper planning with forecast exercises to monitor the provisions of care and ensure enough resources for all patients with limited resource wasting is necessary. For this we need to look in to past projections of patient coming to the hospitals and the observed hospital service used during that time. Then we need to make future space adjustments based on patient needs rather than using a blind approach. Such a study was conducted by Bouckaert, Heed and Voorde where a projection was made in 2005 for until 2015 and the actual observations results were compared with the original projections". Although 'forecasting the future is neither easy nor certain', a good forecast is much better than a fixed value and helps in making wise decisions ${ }^{10}$.

\section{CONCLUSION}

Hospital services can be improved when employees will become dedicated to their work place. This is only possible if employees are respected and given a sense of belonging; if their problems are addressed and solutions given as early as possible.

Identifying the factors responsible for hospital services and implementing the aforesaid recommendations can help mitigate the problems faced by both staff and patients and hence benefit the entire community and boost up the reputation of the hospital.

\section{RECOMMENDATIONS}

In order to improve the quality of care received by the patients several steps need to be taken by the hospital in charge. Some of these suggestions were given by the respondents themselves. Complaint boxes can be placed for the all category staff that should be accessed directly by the hospital in charge so that unbiased and appropriate investigations can be done regarding the complaint. Placing close- circuit cameras that cover all areas of the hospital and having a security team monitor this 24/7 can reduce chances of theft, abuse, negligence etc.Introducing markers or bracelets for visitors can help separate between trespassers from actual patient visitors.

Among healthcare workers and other hospital staff, first and foremost, recruiting well trained staff to cover essential positions or recruiting new staff and training them well before they become permanent workers is crucial to improving quality of care. Providing guidelines and written protocols which workers can refer to incase they face an unexpected situation can reduce the time taken to solve problems. Unless an emergency situation arises, cleaning staff can be guided to work either before or after general office hours so as to reduce risk of accidents. Constant and regular supervision is necessary to ensure quality of work is up to mark. Hence, unbiased team leader and a counsellor are needed in every ward so as to settle work disputes as well provide incentives and motivational speeches to improve quality of work. 
In case of doctors, working late night hours and for prolonged duration can be stressful. Furthermore, specialist services are provided only in the mornings. Recreational rooms with indoor games, and transport services for late night workers can help alleviate this problem. During day time, it is necessary to ensure timely morning rounds in every ward. Visitor's restriction should be enforced strictly during these hours so as to avoid overcrowding and delay in conducting rounds. Allocation of space for private chambers within the hospital during the evenings can ensure the specialist remains within hospital premises even in the evenings. Thus, patients can take the consultation from specialist doctor they desire without having to look for specialists elsewhere.

In case of surgeries, all peri-operative drugs should be made available within the hospital pharmacies so that patients do not have to look in different places. Obtaining a narcotics drug license and storing adequate supplies of emergency drugs by the hospital pharmacy can reduce hassle for both the patient and the anesthetist.From time to time, all medical and surgical equipment needs to be upgraded or replaced. In wards where critically ill patients are present (CCU, ICU, PICU, NICU, $\mathrm{SCBU}$ ) and in the operation theatre restrict visitors at all times to prevent contamination.

To tackle the problem of over-crowding, transferring certain wards to the new hospital building and increasing the allotted space for the remaining wards in the old hospital building can be helpful.Unutilized spaces in the hospital should be renovated for better utilization
Simple steps such as improving quality of food in the canteens, proper pest control in hospital wards, proper disposal of wastes and improved quality of patient clothing and bedding can reduce anxiety and aggression of patients during their stay in hospital. Installation of a water treatment plant is necessary for providing safe water for use.

For better guidance, a map of the entire hospital at entry point as well as a TV screen in the lobby for general advertising on service provided by hospital, thespecialists available and the number of beds available can be placed. Proper media coverage for advertising newly installed facilities in hospital can increase the number of patients coming to the hospital. Contents on the hospital website should be upgraded daily with the most recent information.

\section{ACKNOWLEDGEMENTS}

The authors would like to thank the participants and the hospital authority for their cooperation.

\section{DISCLOSURE}

All the authors declared no competing interest.

\section{REFERENCES}

1. http://www.surgeryencyclopedia.com/Fi-La/Hospital-Services.html

2. Park K., Preventive and Social medicine, 20th edition, M/S BanarsidasBhanot Publishers. 2009:28

3. Yang M, Fry LW. The role of spiritual leadership in reducing healthcare worker burnout. Journal of Management, Spirituality \& Religion. 2018;15(4):305-234.

4. Beardwood B, Walters V, Eyles J, French S. Complaints against nurses: A reflection of the new managerialism'and consumerism in health care?. Social Science \& Medicine. 1999;48(3):363-374.

5. Raveesh BN, Lepping P, Lanka SV, Turner J, Krishna M. Patient and visitor violence towards staff on medical and psychiatric wards in India. Asian journal of psychiatry. 2015; 13:52-55.

6. Lepping P, Lanka SV, Turner J, Stanaway SE, Krishna M. Percentage prevalence of patient and visitor violence against staff in high-risk UK medical wards. Clinical medicine. 2013;13(6):543.

7. Hahn S, Müller M, Needham I, Dassen T, Kok G, Halfens RJ. Factors associated with patient and visitor violence experienced by nurses in general hospitals in Switzerland: A cross sectional survey. Journal of clinical nursing. 2010;19(23 24):3535-3546.

8. Gates DM, Ross CS, McQueen L. Violence against emergency department workers. The Journal of emergency medicine. 2006;31(3):331-337.

9. Bouckaert N, Van den Heede K, Van de Voorde C. Improving the forecasting of hospital services: A comparison between projections and actual utilization of hospital services. Health Policy. 2018;122(7):728-736.

10. Makridakis S, Taleb N. Decision making and planning under low levels of predictability. International Journal of Forecasting. 2009; 25:716-733. 